\title{
Contemporary quality improvement
}

\author{
Melhoria contemporânea da qualidade
}

Mejora contemporánea de la calidad

\footnotetext{
${ }_{1}$ Medical Management Centre, The Karolinska Institutet, Stockholm, Sweden.

Correspondence J. Øvretveit

Medical Management Centre, The Karolinska Institutet. Medical Management Centre (MMC) Floor 5, Berzelius väg 3, Karolinska Institutet, Stockholm, SE-171 77, Sweden.

jovret@aol.com
}

\section{Introduction}

Brazil faces many challenges in meeting the changing health needs and demands of its population. Quality improvement methods and strategies have a part to play in improving healthcare and public health. This article gives a short outline of some of the methods and strategies which can be used by services and regions to improve healthcare and to reduce waste and costs.

\section{The challenges}

A growing population and economy brings changing health needs and increased demands and expectations for citizens and patients of health services. There are inequalities in access to healthcare and great variations in Brazil in the use of services and treatments as well as in outcomes. The costs of healthcare are rising, making some care unaffordable for certain patients and populations. At the same time there is waste and significant harm caused to patients by unsafe healthcare.

\section{The role of quality improvement}

Quality improvement is a general term referring to:

- A body of systematic knowledge, which some call a science or a multi-discipline;

- A set of methods, many of which have been found to be effective in improving care;

- Different strategies for addressing specific quality and safety problems (eg. hospital acquired infections, or communication problems between services);

- Different programmes for general quality and safety issues (eg. clinical guidelines development or accreditation).

\section{Safety}

Media reports of harm to patients, hospital acquired infection and abuse in older care homes has drawn the attention of politicians and managers to the need to support safety improvements. However few countries provide the sustained programme funding needed for significant improvements over time and for developing a systems approach to safety. One development in which Australia led the field is in policies encouraging doctors and nurses to tell patients of any errors - termed open disclosure ${ }^{1}$. Another 
is attention to the health and well-being consequences for health providers of being involved in an adverse patient event - there are programmes in the USA to support such "second victims" and research on the subject in Sweden.

\section{Quality and health reform}

Health care systems are continually reforming and different countries are influenced by reforms in others. The UK is the country which has perhaps introduced most reforms over the last years and at the same time has made quality and safety a central part of these reforms. For quality specialist and patients, possibly the most important part of the reforms have been targets for waiting time with penalties for services which fail to meet targets. Quality improvement and "lean" methods have been used with some success to meet these targets. Examples and useful guideline materials can be downloaded from the UK National Institute for Innovation and Improvement web site (http://www.institute.nhs.uk, accessed on 01/Dec/2012).

\section{Finance and purchasing}

Other countries are experimenting with ways to pay providers for quality as well as volume of care ("value based purchasing"). "No pay for never events" is one approach, started in the USA and followed to a limited extent in other counties such as the UK and Sweden. Purchasers will not pay bills for certain procedures such as re-operation for retained object, and some patient readmissions to hospital a short time after discharge. Initially this is symbolic but is part of a wider trend to buy value in healthcare and in health. Other schemes involve paying providers slightly more per patient if they reach certain quality indicator levels, with the extra payments deducted from the payments which would have been made to those not meeting these quality indicators. Payment for quality also means paying for entire episodes of care ("bundled payment") or a set payment for a population. There is also some interest in the UK changing investment strategies in order to improve quality as well as reduce waste, and in estimating and tracking the return on investment of quality projects 2 .

\section{Measurement and accountability}

The movement towards value based financing is one influence that is accelerating the devel- opment of indicators and reporting of quality performance: this is because valid measures are necessary if providers are to be paid for quality as well as for the number of procedures. Other influences are politicians in many countries wishing to ensure choice and competition and to ensure information is available to patients and purchasers to make an informed choice. Other countries have different indicator measurement systems and different ways to report quality information, including public web sites allowing easy comparisons - notable examples are the US Federal Medicare quality reporting system, the UK comparison system, and that used in Denmark. In addition, accrediting bodies have developed extensive quality indicator systems which they require their accredited organisations to contribute to and which they use in accreditation assessments - examples are Canada Accreditation, The Joint Commission and The Australian Council for Standards systems.

\section{Coordination, integration and transitions of care}

Many quality and safety problems arise in the "in betweens": between work-shifts, between professions and between services and sectors. Both the UK and Sweden have examples of integrated care organisations, some for particular groups such as integrated health and social care for older people ${ }^{3}$, and comprehensive integrated systems ${ }^{4}$ which show some evidence of higher quality. The USA is experimenting with different schemes of accountable care organisations 5, and has long established integrated health systems such as Kaiser Permanente, Geisinger, and Henry Ford.

\section{Quality research}

Quality research is not only what researchers do. In fact most quality research is carried out by practicing nurses, doctors and project leaders. Collecting and interpreting data to decide what to change and whether a change is an improvement requires some basic skills and knowledge of research methods. One trend is for practicing quality improvers to strengthen the validity of their assessments of quality projects using better methods for data collection and evaluation. More international quality conferences such as the International Society for Quality in Health Care (ISQUA) conferences are featuring local projects. In addition there are international quality project web sites which invite and pub- 
lish the experiences and findings from practical quality projects and these can be searched by problem or by method: the two best examples are the US Agency for Healthcare Research and Quality (AHRQ) innovations exchange, and the US Institute for Healthcare Improvement (IHI) case studies data base.

A further international trend is for research funding agencies to finance more applied and practically-relevant quality and safety improvement research using action research and collaborative research methods. Some of the findings from this type of research into implementation and spread methods is particularly relevant to Brazil (http://med.stanford.edu/rmg/funding/ funding_digest_06_23_11.html, accessed on 01/ Dec/2012).

\section{Conclusions}

This overview showed different approaches for improving quality, some of which may be less well known in Brazil. It also noted guidance and resources developed elsewhere which can help apply the methods. Which are most cost-effective and most appropriate will depend on the operating environment of a local service. Also, on that service's capacity for change: some complex approaches, and some requiring quality-supporting information technology, may not be possible in some services, even with external expert assistance. However, quality improvers can learn from many other countries about which approaches are effective and find and use resources and how to implement them as many problems and solutions at the clinical level are common across the world.
1. Australian Council for Safety and Quality in Health Care. Open disclosure standard: a national standard for open communication in public and private hospitals, following an adverse event in health care 2003. http://www.safetyandquality.org/arti cles/publications/opendisclosure_web.pdf.

2. Øvretveit J. Summary: do changes to patient-provider relationships improve quality and save money? London: The Health Foundation; 2012. http:// www.health.org.uk/publications/do-changes-topatient-provider-relationships-improve-qualityand-save-money.

3. Ham C, Dixon J, Chantler C. Clinically integrated systems: the future of NHS reform in England? BMJ 2011; 342:740-2.

4. Øvretveit J, Hansson J, Brommels M. An integrated health and social care organisation in Sweden: creation and structure of a unique local public health and social care system. Health Policy 2010; 97:113-21.

5. Fisher E, Shortell S. Accountable care organizations: accountable for what, to whom, and how. JAMA 2010; 304:1715-6.

Submitted on $31 / \mathrm{Dec} / 2012$

Approved on 02/Jan/2013 